Fanum

Sociológico
Forum Sociológico

Série II

23 | 2013

Número 23

\title{
As artes de fazer o comum nos estabelecimentos de ensino: outras aberturas sociológicas sobre os mundos escolares
}

José Manuel Resende e Luís Gouveia

\section{(2) OpenEdition}

Journals

Edição electrónica

URL: https://journals.openedition.org/sociologico/853

DOI: 10.4000/sociologico.853

ISSN: 2182-7427

Editora

CICS.NOVA - Centro Interdisciplinar de Ciências Sociais da Universidade Nova de Lisboa

Edição impressa

Data de publição: 1 novembro 2013

Paginação: 97-106

ISSN: 0872-8380

Refêrencia eletrónica

José Manuel Resende e Luís Gouveia, «As artes de fazer o comum nos estabelecimentos de ensino: outras aberturas sociológicas sobre os mundos escolares», Forum Sociológico [Online], 23 | 2013, posto online no dia 01 janeiro 2014, consultado o 31 março 2022. URL: http://

journals.openedition.org/sociologico/853 ; DOI: https://doi.org/10.4000/sociologico.853

Este documento foi criado de forma automática no dia 31 março 2022.

(C) CICS.NOVA 


\section{As artes de fazer o comum nos estabelecimentos de ensino: outras aberturas sociológicas sobre os mundos escolares}

José Manuel Resende e Luís Gouveia

\section{NOTA DO AUTOR}

Os dados apresentados são retirados do projeto financiado pela Fundação para a Ciência e a Tecnologia (FCT-MCTES) "Género, Desigualdade e Humilhação: sentimentos de injustiça nas escolas", aprovado em 2008 com a referência PIHM/GC/0085/2008.

\section{E tudo o vento levou após o processo de democratização escolar? Formas de qualificação dos seres no centro das operações críticas dos alunos}

Parece estranha esta interrogação. Contudo, esta indagação continua a ser central nas abordagens sociológicas sobre os processos de escolarização, mesmo quando estas ensaiam outras aberturas analíticas sobre os mundos escolares experienciados por adultos e não adultos.

De facto, os mundos escolares são povoados por seres qualificados através de figuras institucionalizadas (que no plano jurídico assumem determinados estatutos), mas, apesar destas precisões, os seus sentidos extravasam os coletes de forças que daquele entendimento se pressupõem a partir de uma leitura estrita. Tais espargimentos de sentidos são trazidos pelos múltiplos momentos de que se tecem as vivências escolares, quer aquelas que ocorrem nas salas de aula, quer as que acontecem em outros espaços. 
Assim, é nosso propósito neste texto trazer outros conceitos analíticos que nos possam ajudar a compreender como professores e alunos, apesar dos figurinos juridicamente determinados, atuam no espaço escolar na procura daquilo que é comum; de que modo, nas sociabilidades de uns com os outros ou entre pares, convocam nos seus eixos atuantes outras representações e sentidos que não se encerram nos estatutos qualificados por aquelas designações. Traçar aquilo que é comum nas sociabilidades escolares a partir da perceção operada em ações pelos alunos convida-nos a especificar um pouco melhor de que estabelecimentos de ensino e de que alunos falamos quando ensaiamos o olhar etnográfico em 6 escolas do Ensino Secundário localizadas em diferentes concelhos do continente português.

Dos 6 estabelecimentos de ensino escolhidos, 1 localiza-se num concelho a norte do distrito de Aveiro, 4 em dois concelhos do distrito de Lisboa e 1 num concelho do distrito de Portalegre. Dos alunos inquiridos e entrevistados em cada uma das 6 escolas, a sua caracterização sociológica é contrastante, sendo, por isso, possível determinar tendências gerais que do ponto de vista da sua origem social marcam cada um destes espaços, diferenciando-os dos restantes (ver também Anexo).

Tendo então em consideração a morfologia sociológica de cada uma destas 6 escolas, é possível afirmar que em duas das escolas do distrito de Lisboa os alunos são oriundos sobretudo de diversas frações das classes médias urbanas. Apesar desta aproximação numa destas duas escolas, as frações das classes médias mais qualificadas encontram-se mais representadas do que na outra escola.

As outras duas escolas do distrito de Lisboa e a escola do distrito de Portalegre recrutam alunos oriundos sobretudo de meios populares, não obstante a presença de outros, com representação menos significativa, que estão localizados nas frações das classes médias urbanas. Finalmente, na escola a norte do distrito de Aveiro, verifica-se a interseção de alunos localizados nas classes populares ligadas à agricultura e a pequenas empresas e com baixas qualificações escolares da parte dos seus ascendentes.

Uma vez que o propósito central da investigação ${ }^{1}$ é o de captar as perceções de injustiça produzidas nas escolas secundárias pelos alunos tendo em conta o seu género, o trabalho é conduzido, sobretudo, na base de duas frentes observacionais. De um lado, realizaram-se entrevistas (65) a discentes a frequentar o 12.. ano de escolaridade; do outro, lançou-se um inquérito por cenários ao conjunto de alunos matriculados em 2010/11 no ano terminal do secundário (Resende, Dionísio e Caetano, 2012). Neste artigo trabalhamos exclusivamente informações tratadas das entrevistas realizadas a um conjunto de alunos escolhidos para o efeito ${ }^{2}$.

Ao eleger como eixo central da investigação as relações entre as perceções das situações injustas na escola e o género declarado pelos alunos, a equipa de investigadores procura, por um lado, identificar possíveis clivagens entre aquelas perceções segundo o género, mas também cruzar aqueles mesmos entendimentos com as suas origens sociais. Contudo, este eixo relacional requer outros acrescentos adicionais de modo a precisar com mais clareza o significado sociológico do conceito "perceção injusta" de situações escolares.

A opção de captar as perceções injustas parece-nos mais adequada do que o seu contrário. Isto é, dar o centro às considerações sobre as injustiças experienciadas na escola pelos alunos tem sido a melhor forma para, a partir delas, chegarmos aos seus juízos sobre as medidas do justo que atribuem às diferentes circunstâncias que assinalam nas entrevistas. Mas ir do injusto ao justo não é a única escolha assumida. 
Para fundar com mais rigor os "sentimentos sobre as vivências factuais do injusto" na escola, o raciocínio sociológico aqui presente faz invocar duas outras questões que estão diretamente associadas a situações de carga injusta.

De um lado, aparecem as situações de desigualdade que são habitualmente reclamadas pelos discentes. As desigualdades de apreciação dos professores em relação às suas qualidades pessoais, sociais e cognitivas são questões tidas em conta. No entanto, estas não são as únicas situações de desigualdade apuradas. Outras deslocam-se para as formas de tratamento de uns para com os outros, em reciprocidades cruzadas, onde também intervêm as relações interpessoais entre os pares, ou relações mais extensivas que implicam conjuntos mais amplos de outros.

Tomar como referencial as situações de desigualdades experienciadas pelos alunos nas artes de fazer o comum nas sociabilidades escolares, quer entre eles e os adultos, quer entre eles, os seus colegas e amigos, não esgota o questionamento sobre os "sentimentos de injustiça escolar". Seguindo este raciocínio, esta análise não deixa de considerar como relevantes outras situações enunciadas pelos entrevistados e que fazem deslocar o olhar para outros enquadramentos experienciais, quer de natureza discriminante, quer de caráter humilhante. As reclamações que enunciam a partir de narrativas, que por sua vez convocam situações concebidas pelos inquiridos como não ajustadas à sua dignidade como seres humanos, trazem para a reflexão outras referências normativas que não deixam de estar presentes nas suas formas de agir em comum.

Dar ênfase às operações críticas realizadas pelos alunos a partir de situações escolares por estes mencionadas nas entrevistas como suscetíveis de os confrontar no seu ajuizamento sobre o que é comum a todos na escola leva-nos a considerar o estabelecimento de ensino como uma "arena pública", de um lado, e, simultaneamente ao se assumir esta referência conceptual, os seus espaços enquadram uma pluralidade de experiências passíveis de os tornarem capazes de questionar as formas de qualificação que por ali são trabalhadas por uns e por outros, mas em particular, que são investidas pelos professores (Resende, 2010), do outro lado. Assim, as salas de aula, a cantina, a biblioteca, ou simplesmente o espaço do recreio são contextos qualificantes a partir dos quais os alunos retiram das suas experiências ali vividas um sem-número de ocorrências que são identificadas como problemáticas, e a partir das quais alguns dos seus temas são elevados a categorias de provável ou eventual disputa visível ou invisível. As formas de visibilidade das denúncias ou das expressões de indignação atuantes são umas vezes distintas, mas outras vagas ou indefinidas. Desde a confrontação direta com o ou os acusados de onde decorrem atos comunicacionais que se desenrolam com ou sem altercações diversas, a discussões resultantes de ações consideradas indisciplinadas ou a movimentações mais violentas até aos silêncios prolongados que mostram abdicações de graus variáveis, os acontecimentos que os espoletam ao longo das suas trajetórias fazem prova das suas vinculações no sentido de tornar suportável a vida comum na escola. 


\section{Transformações no sistema de ensino e nas sociabilidades dentro do espaço escolar. a nova ética na relação entre professor e aluno}

Novas orientações em matéria de política educativa para a escola europeia marcam transformações profundas nos sistemas educativos nas últimas décadas (Resende, 2003; Almeida e Vieira, 2006). Novos públicos escolares, oriundos de meios sociais e étnicos mais afastados do universo cultural transmitido na instituição escolar, passam a protagonizar percursos escolares mais longos no sistema de ensino - trajetórias das quais estavam até então apartados (Resende, 2010).

A este esforço de massificação da escolaridade corresponde uma orientação política centrada no modelo de desenvolvimento económico. O desígnio de progresso nos indicadores de escolaridade serve o horizonte de melhoria do desempenho económico dos respetivos países. Organismos internacionais cumprem um importante papel nesse desiderato. Os resultados periodicamente apresentados em estudos internacionais (como o programa PISA, da OCDE) são acompanhados de orientações, diretivas, no sentido de melhoria do desempenho dos sistemas educativos segundos os parâmetros partilhados. Este predomínio do modelo de análise dos resultados escolares assente em informação estatística, mensurável, quantificável, tem repercussão igualmente no trabalho estatístico a nível nacional e consequentes reflexões em matéria de política educativa (Dionísio, 2010).

A constituição e publicação de rankings escolares, que ordenam os estabelecimentos de ensino do país em função dos resultados alcançados pelo respetivo corpo de alunos, são disso ilustração. Concomitantemente, ganha terreno o modelo de relação entre escolas segundo uma lógica mercantil. Aos encarregados de educação é dada liberdade de escolher a instituição escolar dos seus educandos em função exatamente das informações recebidas relativamente aos resultados escolares obtidos (Melo, 2007). É o funcionamento de um mercado escolar, segundo um modelo de concorrência enquanto princípio de justiça de salvaguarda da escolarização como bem comum (Derouet, 1992).

Esta evolução no que respeita à escolaridade acarreta necessariamente importantes mutações nas sociabilidades dentro do espaço escolar em virtude da diversidade na composição morfológica que nele passa a observar-se. Além de segmentos de alunos pertencentes a classes sociais mais desfavorecidas, o número de alunos de nacionalidade não portuguesa aumenta nos estabelecimentos de ensino, onde, além de constituir um grupo onde se verifica frequentemente um afastamento intergeracional em relação à instituição escolar, um diferencial entre a língua que estes alunos cultivam no espaço doméstico e a que é lecionada nas escolas dificulta o seu ajustamento à cultura escolar (Resende, 2010). Por outro lado, esta última é fragilizada pelo consumo de produtos culturais provenientes dos novos suportes de difusão de informação dos meios de comunicação de massa. Estas indústrias culturais têm nos jovens os seus potenciais consumidores e assumem particular importância na configuração das sociabilidades dos adolescentes e jovens na escola e na sua resistência face aos saberes que esta instituição valoriza (Barrère, 2002). Acresce pois para os professores um trabalho de motivação de alunos que evidenciam uma relação débil com os conteúdos disciplinares que são lecionados - tanto na preparação dos suportes pedagógicos como na própria avaliação. 
A distância demonstrada pelos jovens em relação às expectativas da instituição escolar relativamente à sua socialização política conduz ao que Rayou (2007) descreve como uma reapropriação da sua experiência no espaço escolar. Estes jovens desenvolvem no espaço escolar comportamentos para "resistir ao stress induzido pela seleção escolar" (idem: 19), pelo insucesso escolar que experimentam. Os alunos desenvolvem um "eixo de socialização horizontal" (idem: 18) que interfere com o eixo de socialização vertical e constrange a ação dos adultos que o suportam. De uma situação em que os únicos critérios de sociabilidade são quase todos de caráter escolar, passam a coexistir também critérios de sociabilidade adolescente e juvenil. Este modelo de conduta dos alunos no espaço escolar tem como principal referência a noção de philia, que fundamenta uma nova ética de relação entre professores e alunos e na qual, como se procura demonstrar, a noção de respeito assume particular relevância.

\section{A Cité invisível: a gramática de philia na estruturação da experiência no espaço escolar entrecruzada com o sentido do justo}

O artigo centra-se nas perspetivas dos alunos na modelação da sua experiência no espaço escolar. Tal análise implica a adoção de um olhar não adultocentrista (Rayou, 2005) para um acesso às categorias específicas da experiência social adolescente e juvenil, às suas formas de viver em conjunto, aos conceitos de justiça subjacentes, às lógicas de ação que sustêm os seus comportamentos e condutas. O pressuposto da existência de uma outra escola secundária, como descreve Rayou, de uma outra forma de viver em conjunto que os alunos constroem entre si e com regras distintas daquelas que formalmente enformam a instituição escolar, implica um olhar sobre as justificações e sentidos de justiça com base nos quais os jovens orientam as suas ações e estruturam a sua experiência social. É esse enfoque sobre os juízos portadores de generalidades produzidos que permite penetrar nas construções da vida política dos jovens. Concretamente, sendo o regime da philia um modo particular de vida em conjunto, com especificidades que o distinguem de outros universos com os quais rompe, o não desligamento dos princípios de justiça da escola republicada torna esta gramática juvenil opaca (Rayou, 1998; Resende, 2010).

Rayou desenvolve o modelo de competência que designa por philia a partir do modelo desenvolvido por Luc Boltanski e Laurent Thévenot em On Justification ([1991] 2006). Esta competência resulta de interceção de dois tipos de universos distintos.

De um lado, o universo da justiça. Neste, os indivíduos são objeto de classificação que os diferencia segundo diferentes princípios de equivalência. De outro lado, o universo do amor. Este assenta já no pressuposto da inexistência de hierarquia entre os indivíduos. O próprio ato de classificação constitui um insulto ao amor. A philia oscila pois entre o amor e a política.

Como preconiza Boltanski ([1990] 2012), ao contrário do regime da justiça, o amor ignora todas as referências a equivalências genéricas para o confronto entre as partes. A amizade parece desempenhar um papel intermédio, permitindo a oscilação entre situações de procura de justiça e a superação dessas situações no amor. Nos jovens, a amizade, ou a philia, constitui o princípio de organização quotidiana da sociabilidade juvenil e o refúgio de indiferenciação e proteção de provas de toda a natureza e, com 
isso, o suporte das denúncias de um sistema escolar diferenciador e da recusa de confrontação entre desempenhos escolares, visuais e opiniões (Rayou, 1998).

A paz manifesta-se pela ausência de equivalências; a paz exclui, não apenas a violência, mas igualmente as disputas em justiça - através do envolvimento de princípios de equivalência, de modo a impor uma ordem de grandeza sobre pessoas por intermédio de provas. No estado de paz, as equivalências são inúteis. Sem disputa, não há necessidade de ordenação (Boltanski, [1990] 2012). A reciprocidade regula a relação de amizade, philia. Esta pressupõe um preexistente princípio de equivalência que permite primeiramente avaliar os respetivos méritos de reciprocidade e, depois, controlar a reciprocidade e a equidade das trocas entre si. Como refere Boltanski, a reciprocidade na amizade não é exercida de forma cega; ela é objeto de expectativa relativamente à equivalência da contribuição de cada uma das partes (idem).

É com base na philia que se desenvolve aquilo que Rayou define como uma cultura de reticência (mais do que uma cultura de resistência) e de dúvida face às normas e valores do universo escolar (Rayou, 1998). O princípio de philia, enquanto reivindicação atuante, constitui um meio para proteção dos efeitos desvalorizadores e estigmatizantes da relegação e humilhação escolar, constitui uma forma de resposta ao desencantamento escolar e à afetação da imagem de si.

Nomeadamente, a philia sustenta a construção de uma Cité invisível que rege as relações entre os jovens e que os adultos não compreendem. Como manter a ideia (ou ilusão) da existência de uma comunidade fraternal num mundo escolar que prepara para a divisão dos destinos sociais. As relações de amizade visam preservar numa comunidade de iguais o máximo de tempo possível, sem diferenciações provenientes de provas perspetivadas como injustas. Estas redes de amizade estão impregnadas na experiência adolescente tendo em vista retardar e suavizar a passagem à vida adulta (Rayou, 2007).

Nesta ótica, o que ressalta da atuação dos alunos é a conceção da escola como espaço de convívio entre pares, e menos como território da sua formação escolar enquanto cidadãos.

Nos seus modos de atuar observa-se a presença e também uma deslocação das marcas do regime de philia para o regime do justo quando as reclamações também se dirigem à exigência de igualdade de tratamento entre adultos e não adultos. É notória a rejeição de formas de discriminação positiva: "É assim, há um professor e dentro de uma turma há sempre esse professor que tem preferência por A ou B ou C. É assim, nós não estamos a criticar porque talvez em algumas disciplinas que nós sejamos os privilegiados. Mas não concordamos com isso apesar de nós sermos também os escolhidos" (Entrevista 13: género feminino, Escola Secundária Maria Amália Vaz de Carvalho, Línguas e Humanidades). É sobre o princípio da igualdade que a crítica a um tratamento preferencial por parte dos docentes assenta: "Eu acho que a escola devia-nos transmitir essencialmente igualdade. Eu acho que não é isso que acontece. [...] Como, normalmente consigo ver professores que têm preferência por uns alunos, têm preferência por outros; $e$ isso acontece regularmente, com muita frequência até" (Entrevista 15: género feminino, Escola Secundária Maria Amália Vaz de Carvalho, Ciências e Tecnologias).

A ausência de tratamento diferencial traduz-se mesmo na rejeição de atitudes de complacência por parte dos professores no que respeita às dificuldades sentidas por alunos: "O que acontece é às vezes darem demasiado valor ao esforço. 0 esforço é claro que é importante mas... E aqui acontece-nos bastante pessoas que, por exemplo, têm mais dificuldades, mas que se esforçam mais e têm melhores notas do que pessoas que têm menos dificuldades mas 
que se esforçam menos. Isso é um pouco injusto!" (Entrevista 16: género masculino, Escola Secundária Maria Amália Vaz de Carvalho, Artes Visuais).

\section{Sob o signo do respeito: o olhar estudantil sobre a justiça e humilhação no espaço escolar}

A questão da igualdade de tratamento no espaço escolar verifica-se estar intimamente ligada à ideia de respeito, e estar presente nas relações de autoridade entre as figuras do professor e do aluno. $O$ regime de philia enquanto modelo de regulação política entre os jovens tem particular reflexo na polarização observada dos alunos na ideia de respeito quando produzem juízos relativamente ao seu estabelecimento de ensino e ao respetivo corpo docente e funcionários.

Patrick Pharo (1997) preconiza, de um ponto de vista de uma sociologia centrada na experiência e motivações práticas dos atores sociais, que o respeito consiste numa noção que liga o sujeito ao objeto respeitado de uma forma particular. 0 respeito constitui uma posição prática da primeira pessoa que consiste neste limitar a sua liberdade de ação de forma a não infringir o valor eminente que ela reconhece a uma pessoa ou a um objeto atribuído ou ajuizado como expectável a ser atribuído a um e a outro (Pharo, 2001). Existe portanto um reconhecimento desligado de contingências da comparação social e hierarquização e, nessa medida, uma subtração do indivíduo de provas e consequente classificação social.

Por outro lado, quando um objeto ou indivíduo é ajuizado como digno de respeito, tal não ocorre apenas nos limites do ponto de vista do sujeito que respeita. Esse juízo é estendido, para o indivíduo que respeita, a todos os seres capazes de demonstrar respeito; o respeito é partilhado por todos (Pharo, 1997). E é nessa medida que o respeito pode constituir o principal entrave à aplicação do princípio da justiça. A colisão com o princípio de respeito pode conduzir à perda das justificações que sustentam a ação assente na justiça ou a causa de justiça que justifica essa ação pode-se transformar numa causa de desrespeito (idem).

Ora, o respeito é um princípio particularmente invocado pelos alunos quando estes se exprimem sobre o justo no âmbito das atividades escolares e nas várias situações de interação nestas ambiências onde as questões da justiça estão envolvidas. Como refere Rayou (2007), pode-se falar de uma hipertrofia da perspetiva do respeito nas leituras críticas dos alunos às contradições dos atos ligados à socialização política, quer do lado da transmissão dos conhecimentos, quer do lado das reparações das condutas. Os alunos reivindicam o respeito como princípio de justiça assegurador da sua dignidade enquanto indivíduos, independentemente das diferenças nos desempenhos escolares ou outros critérios.

Nesta ótica, os alunos veem no desrespeito demonstrado pelos adultos para com os jovens no espaço escolar a principal causa dos problemas gerados. Como refere um aluno: "Principalmente eu acho que respeito mútuo deve haver, tanto por parte dos alunos como dos professores. Alunos, funcionários. Professores, funcionários. Porque há muitos professores que desrespeitam os funcionários. Não só os alunos como também os funcionários. E acho que é o que falta muito nas escolas, é isso, o respeito mútuo" (Entrevista 26: género feminino, Escola Secundária Luís de Freitas Branco, Técnico de Gestão do Sistemas Informáticos). 
Essa relação assenta na forma mais ou menos respeitosa como a palavra é dirigida aos alunos: "Pois, lá está. Normalmente são os professores que fazem participação dos alunos, e muitas vezes os alunos passam pelos maus da fita, quando muitas vezes, quem começou a falta de respeito não foi o aluno, mas o professor, pela forma como se dirigiu." (Entrevista 8: género masculino, Escola Secundária Maria Amália Vaz de Carvalho, Ciências Socioeconómicas).

$\mathrm{O}$ respeito assume a forma de reconhecimento da autoridade do professor mas com o pressuposto de reciprocidade. A ordem hierárquica vertical no espaço escolar parece ser substituída por uma ordem negociada (Resende, 2011). Essa horizontalidade na relação entre professor e aluno transparece em várias declarações de alunos entrevistados: "E é assim, eu pessoalmente não me calo, tenho que dizer as coisas na cara, mesmo que seja... Pode ser professor, pode ser o Papa, pode ser a minha mãe, pode ser o pai, há que haver respeito [...]. Porque eu acho que o professor não se deve sobrepor sobre o aluno, mas também o aluno não deve achar que, pronto, que é um ser que tem, que é inferior ao professor e também não é achar que deve obedecer a tudo, não é?!" (Entrevista 26: género feminino, Escola Secundária Luís de Freitas Branco, Técnico de Gestão do Sistemas Informáticos).

A normatividade previamente vigente no que respeita à relação de autoridade entre aluno e professor dá lugar a uma relação em novos moldes. Sem contestar a autoridade do professor, os alunos orientam-se pela expectativa de uma relação pedagógica de respeito mútuo. Essa perspetiva, de resto, estende-se a todos os representantes da figura dos adultos no estabelecimento de ensino (não apenas aos docentes): "Por serem adultos pensam que os alunos automaticamente têm que ter respeito por eles, sem eles terem respeito pelos alunos. [...] Os alunos têm que ser respeitados para que os possam respeitar, ou seja, porque sem o respeito... Eu sou uma pessoa que respeita quem me respeita não respeito quem é mais velho que eu, eu sou capaz de faltar ao respeito a uma pessoa de cinquenta anos $e$ ter completamente respeito por uma pessoa de dez anos" (Entrevista 25: género feminino, Escola Secundária Luís de Freitas Branco, Artes Visuais).

A mesma denúncia sob o princípio do respeito pode observar-se igualmente nas observações produzidas relativamente à relação entre os professores e funcionários (seres de menor grandeza): "Não. É mais o contrário, eu sinto mais que os professores tratam, obviamente, alguns, tratam os funcionários de uma maneira muito, muito mal. Do género, "Eu quero este projetor, já". E não é "Pode-me dar esse projetor, se faz favor?", ou "Pode-me trazer?" (Entrevista 26: género feminino, Escola Secundária Luís de Freitas Branco, Técnico de Gestão do Sistemas Informáticos).

Por outro lado, a desigualdade de tratamento ou discriminação está também na base de denúncias produzidas sob a gramática do respeito. $\mathrm{O}$ respeito só pode ser avaliado segundo valores escolarmente neutralizados e ligados ao caráter insubstituível de cada pessoa (Rayou, 2007). É nesse sentido que as denúncias de alunos são dirigidas a comportamentos discriminatórios dos professores com base nas diferenças de desempenho dos alunos: "Mas aquela professora também era ridícula. Havia um colega meu que estava sentado na mesma carteira que eu, se houvesse uma pergunta e ele respondesse, a professora não ouvia. Eu respondia a mesma coisa, exatamente que ele tinha respondido, e ela ouvia a minha resposta" (Entrevista 8: género feminino, Escola Secundária Maria Amália Vaz de Carvalho, Ciências Socioeconómicas).

É também sob a ideia de respeito que as operações críticas dos alunos são direcionadas para situações de humilhação. Se os alunos vivem a inferioridade da sua grandeza numa escola através da forma como são tratados no quotidiano pelos adultos - 
particularmente na figura dos professores -, são frequentes as denúncias dos alunos direcionadas a situações de desrespeito por parte dos docentes perante vulnerabilidades evidenciadas pelos alunos: "Tinha uma colega minha que era assim mais cheiinha e nós 'tavamos a correr, até 'tavamos a fazer a avaliação dos doze minutos e ela houve uma altura em que ela 'tava cansada e parou e a professora virou-se para ela e disse «Mexe esse rabo». Acho que isso não é de todo agradável. [...] Mas isto até pode ser prejudicial $e$ psicologicamente [...] Até para o professor, não fica bem." (Entrevista 29: feminino, Escola Secundária Professor José Lucas Pires, Línguas e Humanidades).

A lógica do respeito interfere igualmente na questão da gestão da proximidade, da distância conveniente (Rayou, 1998) entre professor e aluno. Ao professor é reconhecida a legitimidade de ação de proximidade (Thévenot, 2006). Por um lado, esta horizontalidade de relações numa ética de deveres e de dádivas mútuos abarca igualmente a expectativa de uma ação de proximidade, de atendimento aos problemas e necessidades concretas dos alunos singulares. Como ilustra uma aluna entrevistada: "Se alguém tiver um problema, está perfeitamente à vontade para partilhar com a turma, para pedirem ajuda... Acho que há sempre uma relação. Mesmo com o diretor de turma, em mais que uma situação o 'stôr ajudou-nos em problemas que tínhamos em casa, ou problemas pessoais. $E$ acho que isso é ótimo, cria-se uma relação exterior a professor-aluno" (Entrevista 8: género feminino, Escola Secundária Maria Amália Vaz de Carvalho, Ciências Socioeconómicas).

Por outro lado, onde há espaço para a efetividade, existe também o reconhecimento dos limites dessa horizontalidade de relações. Como Rayou (1998) descreve, um excesso de proximidade acarreta, no entender dos alunos, o desmoronamento da própria situação escolar. É o caso da descrição deste aluno entrevistado: “Ou seja, uma relação, amigável, claro que a distinguir algumas coisas... Ele terá sempre a autoridade dentro de uma sala de aula, mas acho que isso é o mais importante de tudo" (Entrevista 8: género masculino, Escola Secundária Maria Amália Vaz de Carvalho, Ciências Socioeconómicas).

Os jovens reconhecem portanto a manutenção da hierarquia entre alunos e professores na construção da sua relação e com base no respeito mútuo: "[...] porque com essa atitude inicial acaba por não se fomentar logo aquele respeito que é necessário, porque uma coisa são os alunos e outra coisa são os professores. É claro, apesar de ter que haver esse respeito mútuo, é uma coisa... São patamares, "diferentes» que têm de ser assumidos. E depois o que acontece é que se um professor não assume o seu papel de professor, o aluno também não vai corresponder" (Entrevista 10: género feminino, Escola Secundária Maria Amália Vaz de Carvalho, Ciências e Tecnologias). Da mesma forma que denunciam modelos de relações longínquas, os alunos reconhecem a desigualdade de condição entre jovens e adultos e rejeitam uma relação estritamente igualitária - que conduziria a situações de desrespeito de parte a parte. Uma proximidade exagerada potencia a erosão da ordem hierárquica.

A questão do respeito nos juízos críticos dos alunos verifica-se igualmente em injustiças observadas no espaço exterior ao da sala de aula; nos relatos dos alunos, o atendimento no espaço do bar surge com particular frequência: "Mas a maior injustiça no bar é mesmo que os professores chegam e são logo atendidos e nós às vezes estamos ali montes de tempo, porque existem duas filas separadas. [...] Isso já é uma grande falta de respeito" (Entrevista 10: género feminino, Escola Secundária Maria Amália Vaz de Carvalho, Ciências e Tecnologias). Este relato do aluno sugere que a obtenção de favorecimento por parte dos adultos - neste caso em concreto, dos professores - a partir do seu estado de grandeza dentro do estabelecimento de ensino é percecionada como injusta. Em função 
de uma igualização entre jovens e adultos, o transporte da grandeza do professor para o espaço fora da sala de aula é percecionado como ilegítima (Resende e Caetano, 2012).

Por outro lado, segundo também o mesmo princípio do respeito referido, é também aludido o tratamento diferencial entre professores e alunos do ponto de vista das civilidades: "E depois, a maneira, o atendimento também. Aos alunos é: "Que é que tu queres?» A um professor: «Ah, bom dia! Tudo bem?» Acho que a educação faz parte da escola, faz parte em todo o sítio, tanto na biblioteca como no bar. Se estamos a ser educados na escola temos que ser com toda a gente educados... Não só com os professores. E depois acho que também para criarem um respeito pelos alunos têm que se dar ao respeito! [...] Porque é que disse bom dia ao professor e não me disse a mim?!" (Entrevista 19: género masculino, Escola Secundária Luís de Freitas Branco, Ciências Socioeconómicas). A indignação expressa revela a atenção da figura do aluno à questão do reconhecimento na significação daquilo que ele considera como importante: a estima de si pela atenção dada pela estima do outro, do adulto, a si mesmo, a grandeza pequena. É desta reciprocidade feita de coisa menor para o professor, como explicita esta denúncia, que os laços entre ambos são considerados importantes: a dignidade do respeito começa pela mutualidade traduzida no cumprimento. Estes atos são matriciais para a dignidade das relações tecidas de uns para os outros.

As denúncias e juízos críticos produzidos pelos alunos aqui descritos são direcionados, assim, para o que lhes parece serem situações de desrespeito por parte dos adultos. Na sua abordagem a questões de justiça, a noção de respeito assume uma importante base na construção das suas perspetivas. É através dela que são capazes de praticar uma dessingularização das situações sobre as quais a sua análise recai (Rayou, 2007).

De resto, o desrespeito e a humilhação permanecem no centro das reclamações morais contemporâneas. A ativação da referência ao respeito é um elemento persistentemente presente e revelador das expectativas e exigências morais e normativas nas formas de interação com o outro. A noção de respeito, no seu sentido moral, deve ser entendida enquanto constrangimento de civilidade, de rejeição da humilhação do outro, de negação do seu valor - humilhação entendida enquanto forma de injustiça. Do ponto de vista político, a lógica do respeito constitui em si um elemento que se insere nas questões da justiça e construção de eixos de normatividades comuns (Zaccaï-Reyners, 2008).

\section{Fazer o comum na Escola: o respeito e a troca de bens na base da experiência do reconhecimento do outro}

A philia, enquanto laço político autónomo desenvolvido pelos alunos, é sensível, por um lado, às referências cívicas da igualdade, mas também à questão da proximidade entre uns e outros, ao reconhecimento das diferenças - sob o sentimento de respeito expresso pelos alunos. Por sua vez, este imperativo do respeito permite introduzir a questão do reconhecimento do outro.

O reconhecimento, ou a luta pelo reconhecimento (Honneth, 2011), está associado às lutas pela estima social, pela mutualidade enquanto troca de bens. As persistentes alusões dos alunos ao princípio do respeito correspondem à demanda do seu reconhecimento, do reconhecimento da sua grandeza por parte dos adultos dentro do estabelecimento de ensino. A negação do reconhecimento não representa apenas uma 
injustiça, na medida em que prejudica os sujeitos na sua liberdade de ação ou lhes inflige danos; ela refere-se a um comportamento lesivo no qual os indivíduos são ofendidos na compreensão positiva de si mesmos, reconhecimento da sua grandeza pequena, enquanto alunos.

A experiência de desrespeito, de negação do reconhecimento de determinadas reivindicações de identificação de si, pode estimular uma resistência social e um conflito - uma luta pelo reconhecimento. No entanto, como expõe Honneth, tais reações à injustiça do desrespeito não surgem inevitavelmente; elas dependem empiricamente, sobretudo, de como é constituído o meio político-cultural envolvente dos sujeitos atingidos. A experiência de desrespeito está necessariamente entrelaçada num processo de modificações históricas (idem).

As transformações na instituição escolar nas últimas décadas (acima descritas sucintamente) confrontam os professores com o problema prático de construção da ordem escolar (Resende, 2010; Resende e Caetano, 2012), isto é, de uma ordem (re)composta de acordo com uma dada distribuição das grandezas que fundam o que há de comum entre os seres que a habitam. Enquanto a massificação escolar, num contexto de democratização, apela a uma autoridade cuja legitimidade está cada vez mais sujeita a uma pluralidade de provas, e sendo a socialização política dos alunos menos ajustada à ordenação das grandezas que anteriormente enforma o seu espaço, os recursos de autoridade reduzem-se às capacidades argumentativas, relacionais e atuantes dos atores, de uns com os outros (Dubet, 2002). O trabalho do professor não consiste em aplicar as regras e as normas de um estatuto, uma vez que este papel não permite por si só assegurar a ordem escolar dentro da sala de aula. Ele deve em particular fabricar uma relação escolar que não lhe preexiste totalmente (Dubet e Martuccelli, 1998), e atuar em sua conformidade de modo a reduzir, sempre que possível, os efeitos nefastos da ambivalência dos seus gestos que aparecem imbrincados nos regimes de envolvimento das ações recíprocas entre estas duas distintas grandezas.

A exigência do respeito por parte dos alunos sugere expectativas de reciprocidade, de negociação e de horizontalidade na relação construída com as figuras dos adultos - e particularmente com os docentes. Ela é uma demanda pelo reconhecimento, pelo entendimento daquilo que há de comum entre uns e outros no espaço escolar; um processo com caraterísticas sempre flexíveis para a cooperação segundo diferentes princípios de justiça (Resende e Caetano, 2012). A adesão dos alunos, sem prejuízo para o pressuposto da autoridade do professor, depende do reconhecimento por parte dos docentes desta necessidade de construção de compromissos.

Por outro lado, como Ricoeur (2007) preconiza, na dádiva do reconhecimento mútuo, as questões da autoridade legítima têm necessariamente de ser tidas em conta.

Se o reconhecimento decorre do cumprimento das exigências de respeito mútuo, de estima social, esta exigência pode ser concretizada num estado de paz - sem recurso às alternativas da luta e da violência. Aventa o caso das práticas de troca de dádivas mútuas. Nestas trocas, a gratidão assume um papel central para o estabelecimento de uma relação de mutualidade. Na resposta a uma dádiva, a reciprocidade não decorre de forma automática - não existe necessidade mecânica de reciprocar. É nesse sentido que a prática de trocas de dádivas e deveres mútuos coloca em visibilidade, segundo o autor, dois aspetos fundamentais, interrelacionados, do reconhecimento mútuo. Por um lado, ocorre uma troca de dádivas e dons, mas não de lugares, nem de grandezas. As partes envolvidas possuem um caráter insubstituível, sem confluência entre si. Por 
outro, nessa mutualidade é conservada uma distância adequada, integrando o elemento do respeito nessa relação.

É necessário pois ter em conta a assimetria entre o self e o outro nas experiências de reconhecimento mútuo (idem), neste caso entre si próprio e o outro que é espelhado por si, e que se objetiva nas formas de envolvimento recíprocas. As relações verticais de autoridade nas disputas pelo reconhecimento mútuo constrangem as possibilidades de mutualidade - sem contudo colocarem um entrave à própria possibilidade de reconhecimento mútuo. Por outro lado, o respeito e a economia do dom constituem precisamente uma base para garantia desse reconhecimento do outro.

Eis aqui uma outra entrada do olhar sociológico para questionar, e compreender, estas outras arquiteturas de como se faz o comum na escola. Um mergulho etnográfico mais extensivo, e desse modo, mais intensivo, nos espaços que compõem os estabelecimentos de ensino vão-nos ser úteis não só para compreendermos as artes de tecer o comum, os seus fundamentos, as provas de força (Dodier, 2005) a que são sujeitos, mas também para observarmos os exercícios de «investimento de forma» (Thévenot, 1986; Resende, 2010) realizados pelos professores no processo de socialização política escolar cuja relevância social reside nas capacitações de que os alunos dão prova para se mostrarem preparados para confrontarem outros mundos, nomeadamente, o mundo cívico.

A esta entrada uma outra se impõe, pois é necessário um maior aprofundamento em relação àquilo que trazem ao respeito e ao reconhecimento recíproco as experiências que decorrem das relações entre géneros e entre distintas origens de classe. $\mathrm{Na}$ verdade, e tendo exclusivamente por base as informações retiradas das entrevistas, do ângulo do questionamento decorrente das experiências escolares orientadas pelo lado do género, ressalta que é entre os estudantes do género feminino que está mais presente a denúncia de questões de humilhação e de desrespeito perante a vulnerabilidade da figura do aluno.

É também entre elas que está mais patente a alusão à igualdade perante as regras e a igualdade de tratamento entre os seres que habitam a escola. No género feminino, o discurso de denúncia de diferenças no tratamento por parte dos docentes na sala de aula surge com mais frequência. É especialmente a questão do privilégio no trato com os alunos que revelam melhor desempenho escolar que é mais focado pelas alunas. Já no que diz estritamente respeito à atribuição das classificações, a igualdade absoluta na avaliação dos alunos - sob os mesmos critérios e uma mesma bitola, sem atenção a particularismos - surge mais vezes apontada entre género masculino.

Por outro lado, a alusão ao respeito parece encontrar-se mais presente nos juízos produzidos sobre o trabalho dos professores e funcionamento do estabelecimento de ensino entre o género feminino. A condição da reciprocidade no trato, não obstante as reconhecidas diferenças de estatuto entre professor e aluno, parece ser mais evidente nas entrevistas realizadas às alunas.

Numa lógica de igualdade perante as regras, as denúncias de diferenças de tratamento perspetivadas como injustas aparecem também mais frequentemente apontadas entre $o$ género feminino. Desigualdades de tratamento em espaços da escola onde as diferenças de grandeza entre os seres não as justificam - como é caso do atendimento prioritário a professores em espaços como o bar da escola - ou situações de infração a regras da escola por parte dos docentes não devidamente sancionados são as situações mais denunciadas pelas alunas nas entrevistas realizadas. 
Já na ótica da classe social de origem, a reclamação do respeito parece ser transversal aos alunos de todos os meios sociais de origem. Os alunos de todas as escolas e cursos (profissionais e gerais) referem esta questão do respeito na relação entre professoresalunos enquanto elemento estruturador da relação entre estas duas figuras.

Contudo, a questão da manutenção da justa distância na relação entre professor e aluno para assegurar a ordem escolar parece ser mais evidente para os alunos de meios sociais favorecidos. Entre os alunos oriundos de contextos sociais menos favorecidos a questão da entrada do professor na intimidade do aluno é não só mais tolerada, mas também desejada e entendida como parte das funções e obrigações do docente. A manutenção de uma distância adequada no quadro de uma relação eminentemente pedagógica entre discente e docente é já tendencialmente mais privilegiada entre os alunos de meios socialmente mais favorecidos.

Por fim, também a questão da igualdade de tratamento e de avaliação parece estar mais presente no discurso dos alunos de origem social mais favorecida. Em ambos os casos, é sobretudo nos alunos da Escola Secundária Maria Amália Vaz de Carvalho - e dos cursos gerais - que a alusão aos dois temas surge com maior recorrência.

\section{BIBLIOGRAFIA}

ALMEIDA, A. N. e M. M. Vieira (2006), A escola em Portugal. Outros Olhares, Novos Cenários, Lisboa, Imprensa das Ciências Sociais.

BARRÈRE, A. (2002), Les enseignants au travail. Routines incertaines, Paris, L'Harmattan.

BOLTANSKI, L. ([1990] 2012), Love and Justice as Competences, Cambridge, Polity.

BOLTANSKI, L. e L. Thévenot ([2001] 2006), On Justification. Economies of Worth, Princeton, Princeton University Press.

DEROUET, J.-L. (1992), École et Justice. De l'égalité des chances aux compromis locaux, Paris, Édition Métailié.

DIONÍSIO, B. (2010), “O Paradigma da Escola Eficaz entre a Crítica e a Apropriação Social”, Sociologia, 20, p. 305-316.

DODIER, N. (2005), “O Espaço e o Movimento do Sentido Crítico”, Forum Sociológico, 13/14, pp. 239-277.

DUBET, F. (2002), Le déclin de l'institution, Paris, Seuil.

DUBET, F e D. Martuccelli (1998), À l'école. Sociologie de l'expérience scolaire, Paris, Seuil.

HONNETH, A. (2011), Luta pelo Reconhecimento. Para uma gramática moral dos conflitos sociais, Lisboa, Edições 70.

MELO, M. B. P. (2007). "Educação e mass media na modernidade: efeitos na do ranking escolar em análise”, in M. M. Vieira (org.) Escola, Jovens e Media, Lisboa, ICS, pp. 95-108.

PHARO, P. (1997), “Introduction: Justice et respect”, Sciences Sociales et Santé, 15 (1), pp. 9-19. 
PHARO, P. (2001), La logique du respect, Paris, Les Éditions du CERF.

RAYOU, P. (1998), La Cité des lycéens, Paris, L'Harmattan.

RAYOU, P. (2005), “Crianças e jovens, atores sociais na escola. Como os compreender?”, Educação e Sociedade, 26, pp. 465-484.

RAYOU, P. (2007), “De proche en proche, les compétences politiques des jeunes scolarisés", Éducation et Sociétés, 19 (1), pp. 15-31.

RESENDE, J. M. (2003), o Engrandecimento de uma Profissão: Os Professores do Ensino Secundário Público no Estado Novo, Lisboa, FCT e Fundação Calouste Gulbenkian.

RESENDE, J. M. (2010), A Sociedade contra a Escola? A Socialização Política Escolar num Contexto de Incerteza, Lisboa, Instituto Piaget.

RESENDE, J. M. (2011), “Habitar a Escola? Reflexões sociológicas sobre o princípio da ordem hierárquica e o princípio da ordem convivencial na escola secundária portuguesa", in Resende et al. (orgs), I Encontros de Portalegre: Pluralidades públicas do público? Controvérsias em educação, saúde e nos modos de ser solidário, Portalegre, Centro Interdisciplinar de Investigação e de Inovação do IPP, p. 317.

RESENDE, J. M. e P. Caetano (2012), “Da philia à hierarquia na escola: composições da ordem escolar?”, in Resende et al. (orgs.), II Colóquio Luso-Brasileiro de Sociologia da Educação: Habitar a escola e as suas margens - geografias plurais em confronto, Portalegre, no prelo, a editar com e-book.

RESENDE, J. M., B. Dionísio, P. Caetano (2012) “Das experiências de (des)qualificação das pessoas à precariedade dos laços entre os seres que habitam o mundo escolar", Dilemas - revista de estudos de conflito e de controle social, em avaliação.

RICOEUR, P. (2007), The Course of Recognition, Londres, Harvard University Press.

THÉVENOT, L. (1986), “Les investissements de forme”, in L. Thévenot (ed.), Conventions économiques, Paris, Press Universitaires de France, pp. 21-71.

THÉVENOT, L. (2006), L'action au pluriel: Sociologie des régimes d'engagement, Paris, Editions La Découvert.

ZACCAÏ-REYNERS, N. (2008), “Quelques figures contemporaines du respect. Introduction et présentation”, in N. Zaccaï-Reyners (ed.), Questions du respect: Enquête sur les figures contemporaines du respect, Bruxelles, Éditions de l'Université de Bruxelles, pp. 9-30.

\section{ANEXOS}

Tabela 1 送4 Perfis dos alunos da amostra inquiridos e entrevistados segundo origem social e tipo de curso frequentado 


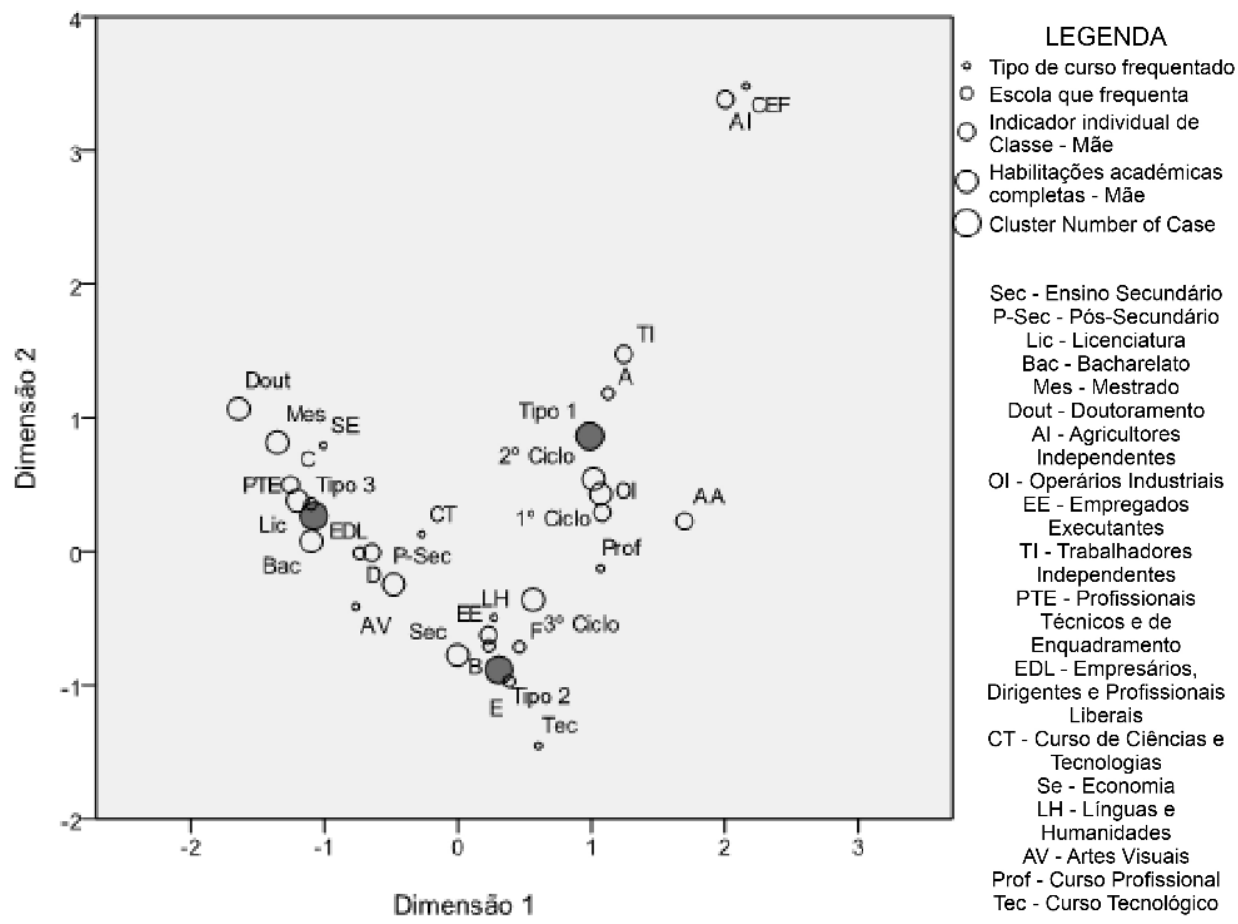

\section{NOTAS}

1. Esta investigação decorre entre 2009 e 2001. E é cofinanciada pela FCT e CIG - Comissão para a Cidadania e Igualdade de Género.

2. Foram realizadas 65 entrevistas para o conjunto das 6 escolas. Mas a sua distribuição por escolas é muito desigual. Por cada entrevista estão presentes, quase sempre, 2 alunos. Mas nem sempre é possível manter este formato. Por vezes só é possível entrevistar 1 aluno. Numa das escolas do distrito de Lisboa em que os alunos matriculados são de origem das classes populares só entrevistámos 1 grupo de dois alunos. Ao invés, na escola do distrito de Lisboa que recruta alunos provenientes das frações de classe média e média alta, a mobilização é maior: são entrevistados 12 grupos de 2 alunos. Ao se optar por entrevistas de grupo, o critério da sua escolha parte de duas variáveis: de um lado confrontar alunos de géneros diferentes e matriculados em cursos diferentes. Também nem sempre se consegue manter os critérios atrás referidos, mas na maioria dos casos os grupos de dois alunos são assim constituídos.

\section{RESUMOS}

o presente artigo procura analisar o modo como os atores escolares constroem as sociabilidades entre si. Num olhar que procura ir além daquilo que os estatutos legais determinam, pretende-se compreender o que é comum nas sociabilidades escolares entre estes atores a partir das perceções dos alunos sobre situações de injustiça no espaço escolar e com base em dados recolhidos num trabalho etnográfico realizado em 6 escolas do Ensino Secundário 
geograficamente dispersas e com populações escolares socialmente contrastantes. Por outro lado, na análise dos juízos críticos manifestados pelos alunos, procura-se identificar igualmente possíveis clivagens segundo o género e origem social dos discentes.

This article aims at examining how school actors build the sociability among themselves. Within a look seeking to go beyond what is determined in the legal statutes, we intend to understand what is common in school sociability among these actors taking the perceptions of students on situations of injustice within school and based on data collected in an ethnography research taken place in 6 Portuguese high schools geographically dispersed and with socially contrasting school populations. Moreover, in the analysis of the critical judgments expressed by students, we also aim at identifying potential cleavages between gender and social origin.

ÍNDICE

Keywords: school sociability, perceptions of injustice, recognition

Palavras-chave: sociabilidades escolares, perceções de injustiça, reconhecimento

\section{AUTORES}

JOSÉ MANUEL RESENDE

Investigador integrado do CesNova da FCSH e membro associado do Observatório da Juventude do ICS da UL (josemenator@gmail.com)

\section{LUÍS GOUVEIA}

Investigador não integrado do CesNova na FCSH e Bolseiro de Investigação da FCT (lcgouveia@yahoo.com) 